\section{INTERVENTION APPROACH TO THE MENOPAUSAL WOMEN IN RURAL BANGLADESH}

Nahid Yasmin ${ }^{1}$, Sayeeda Sultana, ${ }^{2}$ Shahin Akhter Jahan Habib $^{3}$, Khodeza Khatun ${ }^{4}$

\begin{abstract}
:
To compare the level of knowledge about menopause in terms of its cause, problems and care seeking pattern among the rural women after a health education intervention program. It was a cross sectional intervention type study. In the study, the outcome of intervention was obtained by comparing pre intervention and post intervention of same study population to test if there is any difference in knowledge level. The total intervention program was evaluated ranking their answers and found that before the intervention the only $27.8 \%$ respondents had some knowledge regarding menopause related problems and $72.2 \%$ had no such perception. After intervention it was observed that $49.27 \%$ respondents improved their knowledge, statistically it was found significant. The study was conducted to assess and compare the improvement of knowledge of rural women regarding menopause through educational interventions program. From the study findings, it revealed the significant achievement among the respondents regarding the knowledge on menopause, health care seeking behaviour through an educational intervention program imparted to them. The aim of intervention program is that there should be some degree of changes about knowledge, attitude and behaviour. From the intervention program knowledge of the rural women upgraded. Though this study may not necessarily reflect the actual picture. Through the study the intervention program was found very effective which might be replicate in the country through a national program.
\end{abstract}

Key word: Knowledge on menopausal problems, Health care seeking pattern.

\section{Introduction:}

Menopause is a natural hormone (estrogen) deficient state that occurs at the age of $45-55$ years ${ }^{1,2,3}$ After the age of 40 years, ovaries reduce their production of sex hormones ${ }^{3,4}$ As a result, the menstruation as well as other body functions are disturbed. ${ }^{5,6}$ Finally the menstruation cease permanently. This ultimate pause is described as menopause. ${ }^{7,8,9}$ Needless to say that this phase also marks the end of fertility in a women. ${ }^{10}$

1. Associate Professor, Institute of Child and Mother Helath

2. Assistant Professor, Gynae and Obstetrics, BSMMU.

3. Assistant Professor, Dhaka Medical College, Dhaka.

4. Medical Officer, Gynae and Obstetrics, BSMMU.
Irregular periods, hot flashes, night sweats, vaginal dryness and itching, urinary changes, mood swings - all these are typical symptoms of menopause. ${ }^{11,12}$ Osteoporosis (thinning and weakening of bones), heart disease, and Alzheimer's disease (progressive loss of memory and concentration) are the long-term hazards of menopause. ${ }^{13,14}$ With an increase in life expectancy, many years are spent in the postmenopausal phase. ${ }^{15,16}$

In this millennium, women perceives menopause as an opportunity, to concentrate on new activities and bring out the best in her. ${ }^{17,18}$ Consequently, treatment of this transitional phase has now gained more importance than ever before. ${ }^{19,20}$

The current study is an attempt to find out the occurrences of problems related to menopause and their health care seeking pattern and intervention to aware the problem among the women in a rural area of Bangladesh.

\section{Hypothesis:}

Most of the women, especially rural women have inadequate knowledge about menopause and its management; health education intervention program can improve their knowledge, attitude and practice.

\section{Objective:}

General Objective:

To plan, and evaluate a health educational intervention program on menopause and its cause, impact on life style and treatment among the rural women of selected village.

\section{Specific objective:}

1. To assess the existing level of knowledge about menopause in terms of its Cause, problems and care seeking among the rural women of selected Village.

2. To find out the socio-demographic characteristics of rural women of selected village.

3. To compare the level of knowledge about menopause in terms of its cause, problems and care seeking pattern among the rural women after a health education intervention program.

\section{Methodology:}

Types of study:

It was a cross sectional intervention type study. In the study, the out come of intervention was obtained by comparing preintervention and post-intervention of same study population if there is any difference in knowledge level. 
Diagram of a before \& after study

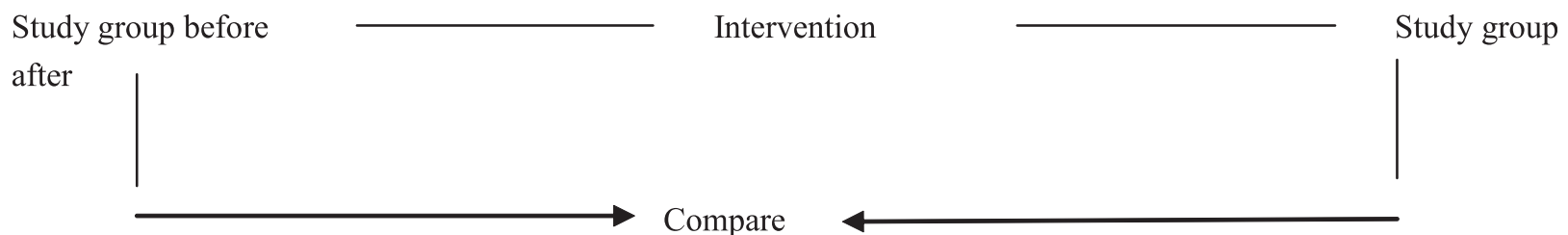

\section{Study Population:}

All the menopausal women of age more than 45 years of a selected village were considered as respondents of the study.

\section{Place of Study:}

Kola village of Laksmipasha Upazilla in Narail district was selected as the study place.

Duration of study:

Duration of the study was three months from August'2006 to October'2006.

\section{Data Collection tools:}

A structured questionnaire was developed based on the objective of the study. The questionnaire was pre-tested on a small number of slum women at nearby slum area to identify any difficulty in understanding by the respondents.

\section{Data Collection procedure:}

The whole procedure was divided in three parts. It consisted of Pre-intervention, intervention and post-intervention.

At first, Formal permission from the local administrative authority was taken, before data collection. Then from the local health workers, a peer group was formed. They were trained for the baseline survey and peer intervention on menopause.

\section{Pre-intervention:}

Researcher herself along with the peer-group conducted faceto-face interview for the baseline survey. After baseline survey on analysis of the baseline data, identification of areas where educational intervention was needed .

\section{Intervention:}

For intervention, the peer group visited all the women (selected) and informed intervention program on menopause. The entire respondents were requested to be present at selected place to participate in the group education.

Interventional program consisted of four elements, with the aim of imparting knowledge about menopause, explaining the term of menopause, enumerating the cause of menopause, recognizing the sign \& symptoms of menopause, explaining the minimization of menopausal sign and symptoms and its general management among the study subjects. It comprised of audio- visual method, didactic method, peer intervention and, two health camp for the menopausal women.

\section{Audio-visual method:}

Educational program was developed by using visual media. We showed a documentary-drama on menopausal symptoms of menopausal women and the handling of their problems by doctors. Expert advices were also picturized at the end of the documentary. It was shown in front of the audience.

\section{Didactic method:}

After the documentary show, the investigator introduced her and conducted the educational session by group approach. She conducted this part of intervention by giving lectures prepared in a manner, so that the participants can understand the message easily. After completion of the session, feed back was taken from the respondents by asking question.

\section{Peer group intervention:}

The peer group constructed from the local health workers, regularly visited the study group and conducted group discussion.

\section{Health camp:}

Post intervention evaluation was done after two months of giving intervention by using same questionnaire. The investigator went to the respondents for post intervention evaluation. The evaluation was done through face-to-face interview of individual respondents.

\section{Data Analysis:}

After collection of data, data were checked, verified and edited for consistency before, tabulating by using the master sheet, computer did the percentage and other statistical calculation and subsequently analysis was done to fulfill the objectives of the study. Result has been presented in the form of tables and graphs. 


\section{Result:}

Table-I: Distribution of respondents by age group.

\begin{tabular}{lcc}
\hline Age Group & $\mathrm{N}=205$ & Percent \\
\hline Age $45-50$ years & 158 & 63.5 \\
Age $51-60$ years & 41 & 20.0 \\
Age $61-70$ years & 19 & 9.3 \\
Age $>71$ years & 15 & 7.3 \\
\hline
\end{tabular}

Table-II : Distribution of respondents by coupling status.

\begin{tabular}{lcc}
\hline Coupling Status & $\mathrm{N}=205$ & Percent \\
\hline Living with husband & 139 & 67.8 \\
Divorcee & 2 & 1.0 \\
Widow & 61 & 29.8 \\
Separated & 3 & 1.5 \\
\hline Total & 205 & 100.0 \\
\hline
\end{tabular}

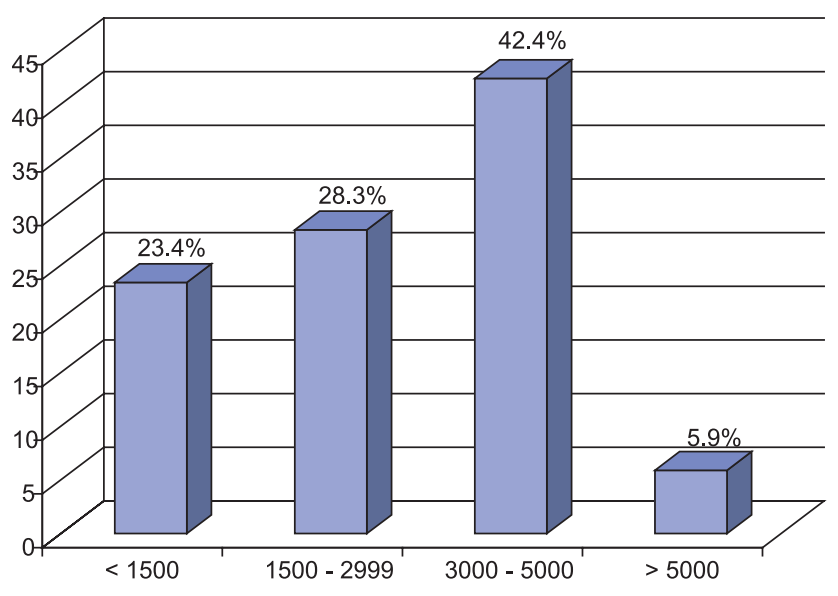

Fig.-1: Distribution of respondents by monthly Family Income.

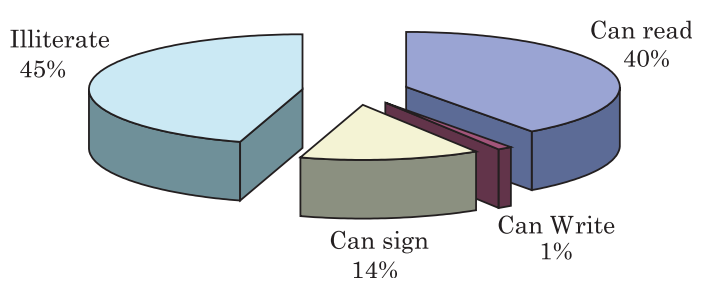

Fig.-2: Distribution of respondents by Literacy level
Table-III: Distribution of respondents by Education level.

\begin{tabular}{lcc}
\hline Education level & $\mathrm{N}=205$ & Percent \\
\hline Primary & 55 & 26.8 \\
Secondary & 22 & 10.7 \\
Higher Secondary & 2 & 1.0 \\
University & 1 & .5 \\
Others & 1 & .5 \\
No formal education & 124 & 60.5 \\
\hline Total & 205 & 100.0 \\
\hline
\end{tabular}

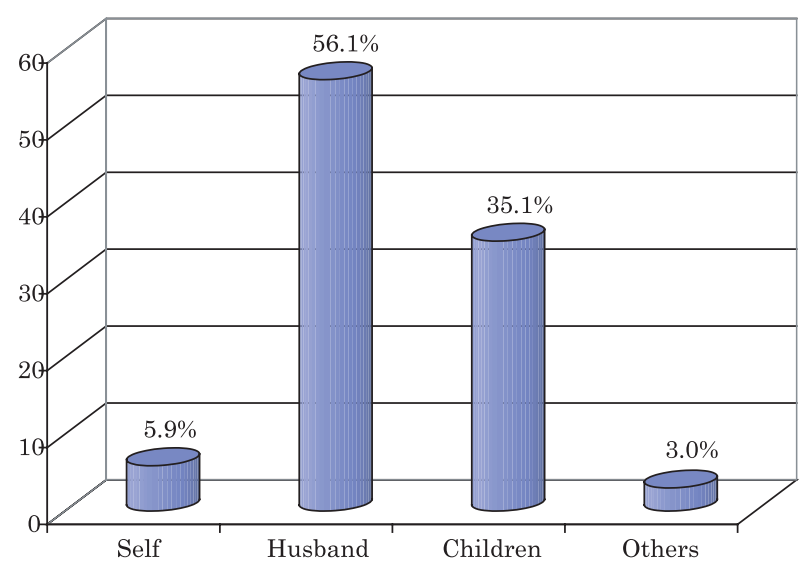

Fig.-3: Distribution of respondents by Economical Dependency

Table-IV: Distribution of women with menopause and different problems

\begin{tabular}{|c|c|c|c|c|}
\hline \multirow[t]{2}{*}{ Problems } & \multicolumn{2}{|c|}{ Menopause } & & \multirow[t]{2}{*}{ Total } \\
\hline & $\begin{array}{c}46-50 \\
\text { Years }\end{array}$ & $>51$ Years & & \\
\hline Something & 6 & 1 & 7 & $X^{2}=1.674$ \\
\hline $\begin{array}{l}\text { coming down } \\
\text { per vagina }\end{array}$ & $5.1 \%$ & $0.9 \%$ & $6.0 \%$ & $\begin{array}{l}\mathrm{df}=3 \\
\mathrm{p}=.643\end{array}$ \\
\hline Burning & 34 & 12 & 46 & $\begin{array}{l}X^{2}=1.801 \\
d f=3\end{array}$ \\
\hline Sensation & $29.3 \%$ & $8.6 \%$ & $39.7 \%$ & $p=.615$ \\
\hline Insomnia & $\begin{array}{c}24 \\
20.8 \%\end{array}$ & $\begin{array}{c}11 \\
9.6 \%\end{array}$ & $\begin{array}{c}35 \\
30.4 \%\end{array}$ & $\begin{array}{l}X^{2}=3.053 \\
d f=3 \\
p=.383\end{array}$ \\
\hline Tiredness & $\begin{array}{c}31 \\
26.7 \%\end{array}$ & $\begin{array}{c}10 \\
8.7 \%\end{array}$ & $\begin{array}{c}41 \\
35.3 \%\end{array}$ & $\begin{array}{l}X^{2}=1.209 \\
d f=3 \\
p=.751\end{array}$ \\
\hline Cramps in upper & 26 & 16 & 42 & $X^{2}=13.974$ \\
\hline \& lower limbs & $22.4 \%$ & $13.8 \%$ & $36.2 \%$ & $\begin{array}{l}\mathrm{df}=3 \\
\mathrm{p}=.003\end{array}$ \\
\hline Back Pain & $\begin{array}{c}21 \\
18.1 \%\end{array}$ & $\begin{array}{c}12 \\
10.3 \%\end{array}$ & $\begin{array}{c}33 \\
28.4 \%\end{array}$ & $\begin{array}{l}X^{2}=19.815 \\
d f=3 \\
p=.000\end{array}$ \\
\hline Sexual & 7 & 4 & 11 & $X^{2}=3.581$ \\
\hline Disturbance & $6 \%$ & $3.5 \%$ & $9.5 \%$ & $\begin{array}{l}\mathrm{df}=3 \\
\mathrm{p}=.310\end{array}$ \\
\hline
\end{tabular}


Table-V: Distribution of respondents by Medical care seeking pattern

\begin{tabular}{lcccccccc}
\hline & $\begin{array}{c}\text { Number of } \\
\text { sufferer }\end{array}$ & \multicolumn{4}{c}{ Medical Care Seeking } & \multicolumn{2}{c}{ Total } \\
\cline { 2 - 7 } & MBBS & Pharmacy & Quack & Homeopathy & Kabiraj & Others & \\
\hline Something coming & 7 & 1 & 0 & 0 & 0 & 0 & 0 & 1 \\
down through vagina & & $2.9 \%$ & $0 \%$ & $0 \%$ & $0 \%$ & $0 \%$ & $0 \%$ & $2.9 \%$ \\
Burning Sensation & 46 & 15 & 0 & 5 & 1 & 1 & 1 & 23 \\
& & $42.9 \%$ & $0 \%$ & $14.3 \%$ & $2.9 \%$ & $2.9 \%$ & $2.9 \%$ & $65.7 \%$ \\
Cramps in upper \& & 40 & 11 & 1 & 4 & 1 & 1 & 2 & 20 \\
lower limbs & & $31.4 \%$ & $2.9 \%$ & 11.4 & $2.9 \%$ & $2.9 \%$ & $5.7 \%$ & $57.1 \%$ \\
Back Pain & \multirow{2}{*}{37} & 10 & 0 & 3 & 0 & 1 & 1 & 15 \\
& & $28.6 \%$ & $0 \%$ & $8.6 \%$ & $0 \%$ & $2.9 \%$ & $2.9 \%$ & $42.9 \%$ \\
Sexual Disturbance & 11 & 4 & 0 & 1 & 0 & 0 & 0 & 5 \\
& & $11.4 \%$ & $0 \%$ & $2.9 \%$ & $0 \%$ & $0 \%$ & $0 \%$ & $14.3 \%$ \\
\hline
\end{tabular}

Table-VI : Distribution of respondents by problems related to menopause.

\begin{tabular}{lcc}
\hline Problems related to menopause & Frequency & Percent \\
\hline Burning Sensation & 51 & 24.88 \\
Insomnia & 16 & 7.80 \\
Tired Ness & 26 & 12.68 \\
Cramps In upper and lower limbs & 59 & 28.78 \\
Low back pain & 57 & 27.80 \\
Sexual Disorder & 10 & 4.88 \\
\hline Total & 227 & 100 \\
\hline
\end{tabular}

Table-VII: Distribution of respondents by the Idea regarding Menopause and its consequences before and after intervention

\begin{tabular}{lccc}
\hline Perception before & \multicolumn{2}{c}{ Perception after intervention } & Total \\
\cline { 2 - 3 } intervention. & Yes & \multicolumn{2}{c}{ No } \\
\hline Having no Knowledge about & 66 & 82 & 148 \\
menopausal problems & $65.3 \%$ & $78.8 \%$ & $72.2 \%$ \\
Having some Knowledge about & 35 & 22 & 57 \\
menopausal problems & $34.7 \%$ & $21.2 \%$ & $27.8 \%$ \\
\hline Total & 101 & 104 & 205 \\
& $100.0 \%$ & $100.0 \%$ & $100.0 \%$ \\
\hline
\end{tabular}

$\mathrm{X}^{2}=4.652, \mathrm{df}=1, \mathrm{p}=.022$

The table shows that before the intervention the only $27.8 \%$ respondents had some knowledge regarding menopause related problems and $72.2 \%$ had no such perception. After intervention it was observed that $44.4 \%$ respondents improved their knowledge. Statistically it was found significant.
Table-VIII : Distribution of respondents by future planning for medical care for their menopausal problem.

\begin{tabular}{lcc}
\hline & $\mathrm{N}=205$ & Percent \\
\hline Doctor & 123 & 60.0 \\
No where & 63 & 30.7 \\
Peer consultation & 19 & 9.3 \\
\hline Total & 205 & 100.0 \\
\hline
\end{tabular}

Table-VIII shows that among 205 respondents reported that for their menopausal problem 123 (60\%) will seek their medical support from MBBS doctor, 63 (30.7\%) reported that they will not go anywhere and 19 (9.3\%) reported that they will take support from their relatives and neighbors.

\section{Discussion:}

Menopause is an important time in a woman's life. Her body is going though changes that can affect her social life, her feelings about herself, and her functioning at work. In the past, menopause was often surrounded by misconceptions and myths. Now, it is recognized that menopause is a natural step in the process of aging. Contrary to the old fashioned view that life is downhill after menopause, many women today find that the years after menopause offer new discoveries and fresh challenges.

The study was a cross sectional intervention type study. Among the total 205 respondents were selected through total house-to -house visit for the study. Majority of the respondents (63.5\%) were of age 45-50 years, next major group (20\%) were within 51-60 years age, 9.3\% were within 61-70 years age group and $7.3 \%$ were more than 70 years. 
By coupling status majority (67.8\%) were found living with their husband, $29.8 \%$ was widow, $1.5 \%$ were divorcee and the rest $1.5 \%$ were found living separated from their husband.

In this study most of the respondents 93(45.3\%) were literate. About 82 (40\%) can read, 2(1.0\%) can write and 28 (13.7\%) can sign only. Most of them 124(60.5\%) had no formal education. About 55 (26.8\%) had primary level of education, 22(10.7\%) had Secondary level education and 1(1.0\%) had Higher Secondary level education $1(0.5 \%)$ had informal level of education. However $1(0.5 \%)$ had University degree.

The study revealed that most of the respondents 115(56.1\%) were dependant on their husband. Thirty five percent respondents were found dependent on their children. Only about six percent were found self-dependant while a few 6(3\%) respondents were found dependent on others.

The current study also find out that among the total respondent who already been experienced the menopause, $12.9 \%$ had urinary problem, $6 \%$ had problem like some thing coming down per vagina, 39.7\% had burning sensation through out body, 30.4\% had Insomnia, 35.3\% had Tiredness, 36.2\% had Cramps in upper \& lower limbs, 33\% had Back pain and 9.5\% had Sexual Disturbance.

It was revealed that among the menopause respondents, who had problem like some thing coming down through vagina only one took treatment from MBBS doctor. Who had Burning sensation majority (42.9\%) visited MBBS doctor. With Cramps in upper \& lower limbs 31.4\%, with Back pain 28.6\% and with Sexual Disturbance $11.4 \%$ visited MBBS doctor.14.3\% visited to MBBS doctor who had urinary problems.

After intervention program it was observed that the respondents who had experienced menopause, $24.88 \%$ respondents could reported Burning Sensation, cramps in upper and lower limbs, Insomnia, Tiredness, Low back pain and Sexual Disorder are the main menopausal symptoms.

While asking them whether they will go for medical care for their menopausal problem among 205 respondents reported that $123(60 \%)$ will seek their medical support from MBBS doctor, $63(30.7 \%)$ reported that will not go anywhere and 19 (9.3\%) reported that they take support from their relatives and neighbors.

The total intervention program was evaluated ranking their answers and found that before the intervention the only $27.8 \%$ respondents had some knowledge regarding menopause related problems and $72.2 \%$ had no such perception. After intervention respondents it was observed that $49.27 \%$ respondents improved their knowledge. Statistically it was found significant.

\section{Limitation of the study:}

1. The current study was conducted among the rural women of one selected village with purposive sample size. So the result of the study may not reflect the exact scenario of the country regarding the existing knowledge on menopause among the women.

2. The aim of any health education intervention program is to improve the level of knowledge on particular aspect to some degree of extent, which may evaluate after a period of time. As allocated time frame for the whole study was limited, changes observed through the current study may not provide representative view of any nationwide health education intervention program.

\section{Conclusion:}

The study was conducted to assess and compare the improvement of knowledge of rural women regarding menopause through an educational intervention program.

From the study findings, it revealed that significant achievement among the respondents regarding the knowledge on menopause, health care seeking behaviour through an educational intervention program imparted to them.

The aim of any intervention program is that there should be some degree of changes about knowledge, attitude and behaviour. From the intervention program knowledge of the rural women upgraded.

Though this study may not necessarily reflect the actual picture. Through the study the intervention program was found very effective which might be replicate in the country through a national program.

\section{Recommendation:}

From the study following recommendations can be drawn:

The government of Bangladesh should give more emphasis on Behavioral change Communication and health Education related to menopausal problem. Health Education for creating awareness regarding predisposing factors and sign symptoms of menopause may be communication. Mass Media, i.e, Newspaper, Television, Radio could be utilized for this purpose.

\section{Reference:}

1. Sallam H, Galal Af, Rashed A. Menopause in Egypt:past and present perspectives. Climacteric. 2006 Dec; 9(6): 421-9.

2. Amore M, Di Donato P,Berti A, Palareti A, Chirico C, Papalini A, Zucchini S.Sexual and psychological symptoms in the climacteric years. Acta Obstet Gynecol Scand. 2005; 80(11): 1071-7. 
3. Anttalainen U, Saaresrsnta T, Aittokallio J, Kalleinen N, Vahlberg T, Virtanen l, Polo O. Impact of menopause on the manifestation and severity of sleep- disordered breathing. Acta Obstet Gynecol cand. 2006;85(11):1381-8

4. Hunter M, Battersby R, whitehead M. Relationships between psychological symptoms, somatic complaints and menopausal status. Climacteric. 1986 Oct:8(3):217-28.

5. Melby MK. Factor analysis of climacteric symptoms in Japan. Maturitas. 2005 Nov-Dec;52(3-4):205-22.

6. Vanwesenbeeck 1,Vennix P, Van de Wiel H: 'Menopaisal symptoms': associations with menopausal symptom and psychosocial factors. J Psychosom Obstet Gynaecol. 2001 Sep; 22(3): 149-58.

7. Melby MK.Climacteric symptoms among Japanese women and men: comparison of four symptom checklists. Climacteric. 2006 Aug;9 (4):298-304.

8. Anderson D, Yoshizawa T, Gollschewski S, Atogami F, Courtney M. Relationship between menopausal symptoms and menopausal status in Australian and Japanese women:preliminary analysis. Nurs Health Sci. 2004 Sep;6(3):173-80.

9. Sierra B, Hidalgo LA, Chedraui PA. Measuring climacteric symptoms in an Ecuadorian population with the Greene climacteric Scale. Maturitas. 2005 Jul 16;51(3):236-45.

10. http://www.hormone.org/public/menopause.cfm
11. http://www.menopause.org/default.htm

12. http://www.mayoclinic.com/health/menopause/DS00119

13. http://www.niapublications.org/agepages/menopause.asp

14. http://womenshealth.gov/faq/menopaus.htm

15. en.wikipedia.org/wiki/Menopause.

16. Pavon de Pazl,Alameda Hernando C,Olivar RoldanJ.Obesity and menopause. Nutr Hosp.2006 Nov0Dec;21(6):633-7.

17. Colombel A,Charbonnel B. Weight gain and cardiovascular risk factors and the post-menopausal women. HumReprod.1997 Oct;12 Suppl 1:134-45.

18. Blumel JE, Castelo- Branco C, Rocongliolo ME, Bifa L, Tacla X, Mamani L. Changes in body mass index around menopause: a population study of Chilean women. Menopause.2001 Jul-Aug;8(4):239-44.

19. Castelo-Branco C,Blumel JE,Roncagliolo ME, Heya J, Bolf D, Binfa L, Tacla X, Colodron M. Age, menopause and hormone replacement therapy influences on cardiovascular risk factors in a cohort of middle- aged Chilean women. Maturitas. 2003 Jul 25;45 (3):205-12.

20. Bosworth HB, Bastain LA, Kuchibhatla MN, Steffens DC, McBride CM, Skinner Cs, Rimer BK, Siegler LC. Depressive symptoms,menopausal status, and climacteric symptoms in women at midlife. Psychosom Med. 2001 Jul-Aug; 63(4):603-8 